\title{
Assumptions about footprint layer heights influence the quantification of emission sources: a case study for Cyprus
}

\author{
Imke Hüser, Hartwig Harder, Angelika Heil, and Johannes W. Kaiser \\ Department of Atmospheric Chemistry, Max Planck Institute for Chemistry, Mainz, Germany \\ Correspondence to: Imke Hüser (imke.hueser@mpic.de) and Hartwig Harder (hartwig.harder@mpic.de)
}

Received: 5 December 2016 - Discussion started: 22 December 2016

Revised: 7 July 2017 - Accepted: 31 July 2017 - Published: 15 September 2017

\begin{abstract}
Lagrangian particle dispersion models (LPDMs) in backward mode are widely used to quantify the impact of transboundary pollution on downwind sites. Most LPDM applications count particles with a technique that introduces a so-called footprint layer (FL) with constant height, in which passing air tracer particles are assumed to be affected by surface emissions. The mixing layer dynamics are represented by the underlying meteorological model. This particle counting technique implicitly assumes that the atmosphere is well mixed in the FL. We have performed backward trajectory simulations with the FLEXPART model starting at Cyprus to calculate the sensitivity to emissions of upwind pollution sources. The emission sensitivity is used to quantify source contributions at the receptor and support the interpretation of ground measurements carried out during the CYPHEX campaign in July 2014. Here we analyse the effects of different constant and dynamic FL height assumptions. The results show that calculations with FL heights of 100 and $300 \mathrm{~m}$ yield similar but still discernible results. Comparison of calculations with FL heights constant at $300 \mathrm{~m}$ and dynamically following the planetary boundary layer (PBL) height exhibits systematic differences, with daytime and night-time sensitivity differences compensating for each other. The differences at daytime when a well-mixed PBL can be assumed indicate that residual inaccuracies in the representation of the mixing layer dynamics in the trajectories may introduce errors in the impact assessment on downwind sites. Emissions from vegetation fires are mixed up by pyrogenic convection which is not represented in FLEXPART. Neglecting this convection may lead to severe over- or underestimations of the downwind smoke concentrations. Introducing an extreme fire source from a different year in our study period and using fire-observation-based plume heights as reference, we find an
\end{abstract}

overestimation of more than $60 \%$ by the constant FL height assumptions used for surface emissions. Assuming a FL that follows the PBL may reproduce the peak of the smoke plume passing through but erroneously elevates the background for shallow stable PBL heights. It might thus be a reasonable assumption for open biomass burning emissions wherever observation-based injection heights are not available.

\section{Introduction}

Transport processes in the atmosphere co-determine local air composition as trace substances can be transported over thousands of kilometres by the wind (e.g. Forster et al., 2001). Long-range transport of pollutants can drastically impair air quality in downwind areas and can trigger exceedances of ambient air quality thresholds (e.g. Vardoulakis and Kassomenos, 2008; Poupkou et al., 2014; Lelieveld et al., 2015). Therefore, the identification of upwind emission sources and the quantification of their impact by atmospheric dispersion modelling is crucial for implementing effective air pollution abatement measures.

Trajectory models are one of the main tools for analysing the transport pathways of air pollution from their source regions to a measurement site. These models track the path of an air tracer particle forward or backward in time in order to establish relationships between the pollution source and the receptor site (Stohl, 1998). Following the recommendation of Stohl et al. (2002), backward simulations with Lagrangian particle dispersion models (LPDMs) are most suitable for the interpretation of atmospheric trace substances measurements. LPDMs calculate the trajectories of a large number of tracer particles in the mean wind and in statistically 
modelled turbulent fluctuations (Rodean, 1996; Stohl, 1998). Since turbulence is stochastic, a large number of trajectories should correctly represent the dispersion of an air mass in the lower troposphere (Stohl et al., 2002). Hence, LPDMs such as FLEXPART (Stohl et al., 1998; Stohl and Thomson, 1999; Stohl et al., 2005) are frequently used to identify source regions of pollution and to quantify their contributions to the atmospheric composition at a measurement site (e.g. Stohl et al., 2007a; Lal et al., 2014). Furthermore, these models are used in an inverse mode to estimate the source strength of emissions. Here, the emission fluxes are adjusted to optimise the agreement between simulated and observed concentrations (Stohl et al., 2009). This inverse method is also applied to validate or improve emission inventories of atmospheric species (Pan et al., 2014).

The methodology in LPDMs is based on the assumption that any regions passed by the trajectories can potentially affect the receptor site. Since emissions from surface sources are distributed over a vertical layer adjacent to the ground, only trajectories passing this so-called footprint layer (FL) (Stohl et al., 2007a) identify effective source regions. Hence, the longer the trajectories reside in this FL height the more pollutants are picked up and transported to the downwind receptor site. Following Seibert and Frank (2004), the trajectories' residence time in the FL height quantifies the sourcereceptor relationship for surface sources when any transport losses are ignored. This source-receptor relationship is a function of space and time that maps quantitatively the relative contribution of pollution sources per unit strength of the emission flux to the air composition at the receptor. Therefore, it is also termed "footprint function", the "source weight function" (Schmid, 1994; Kljun et al., 2002) or "footprint emission sensitivity" (Stohl et al., 2007a). Here, we refer to the general term "emission sensitivity".

Most applications of source quantification with LPDMs in backward mode assume constant FL heights of $100 \mathrm{~m}$ (e.g. Stohl et al., 2007a; Van Dam et al., 2013; Pan et al., 2014), $150 \mathrm{~m}$ (Duck et al., 2007) or $300 \mathrm{~m}$ (Lal et al., 2014). The $100 \mathrm{~m}$ assumption includes typical emission heights for most surface sources as road traffic or industry, that is the height at which pollutants are released to the atmosphere. Furthermore, this height corresponds to the minimum planetary boundary layer (PBL) height typically used in LPDMs. A FL height below this minimum mixing layer height is not recommended in order to obtain sufficient particles for a reasonable particle counting statistics (Stohl et al., 2007b). The vertical mixing of pollutants is linked to the dynamics of the PBL and, therefore, it is subject to strong spatio-temporal variability. For convective conditions, the PBL height reaches up to $2-3 \mathrm{~km}$ and the turbulence mixes emitted pollutants throughout the whole layer on timescales of $15 \mathrm{~min}$ (Stull, 1988, 2006). The PBL should be well mixed and the trajectories evenly distributed within the PBL. In fact, LPDMs use the PBL height to determine the layer over which tracers are effectively mixed, even for stable conditions. The mixing layer dynamics are represented by the vertical distribution of trajectories. The simulation of source contribution from surface emissions is therefore not very sensitive to changes in FL height as long as the height is within the PBL height (Stohl et al., 2007b). Basically, a change in FL height influences the emission sensitivity by two counteracting effects. On the one hand, an increase in FL height leads to a stronger dilution of emission fluxes over this layer - an effect that reduces emission sensitivity. On the other hand, a larger number of trajectories passes through a deeper FL height that increases the residence time for the uptake of pollutants - an effect that increases emission sensitivity. As long as these effects are balanced, it is sufficient to consider only particles up to the expected minimum mixing height (Seibert and Frank, 2004). This is in agreement with the findings in Pan et al. (2014) that different FL height assumptions up to $300 \mathrm{~m}$ have no significant impact on the uptake of surface pollutants. Theoretically, any FL height assumption up to the PBL height should be possible. However, the validity of such an assumption has not yet been analysed. Furthermore, this treatment is only justified for surface emissions. Fire emissions have varying emission heights due to their own dynamics. The fire-induced convection controls the vertical mixing of pollutants within the fire plume that can exceed PBL heights and even reach the lower stratosphere (Andreae et al., 2004; Damoah et al., 2006; Dahlkötter et al., 2014). Therefore, the mixing layer dynamics simulated in FLEXPART underestimates this vertical transport (Duck et al., 2007) and a constant FL height assumption within the PBL height is not justified.

The aim of this study is to quantify the impact of varying FL heights on the results of source quantification. We use backward simulations with the LPDM model FLEXPART that were carried out during the CYPHEX ground campaign in July 2014 to study the source areas and transport routes of air pollution at Cyprus. Results from this detailed analysis of transport routes were used in the study of Derstroff et al. (2017). In Sect. 2 we derive the emission sensitivity function from the simulations and introduce our modifications to calculate the sensitivity for a dynamical FL height. Furthermore, we develop a method to compare the effects of different FL height assumptions. In Sect. 3.1 we compare the emission sensitivity for a constant FL height of $300 \mathrm{~m}$ and a dynamical height derived from local PBL heights. In an application example in Sect. 3.2, we simulate the CO contributions from hypothetical forest fires. Here, we replace the FL heights with the altitude of plume top and quantify the differences in source contributions. Finally, in Sect. 4 we summarise and discuss the results. 


\section{Method}

\subsection{FLEXPART simulations}

We have performed backward simulations with the LPDM model FLEXPART 9.2 (Stohl et al., 2005) during the CYPHEX campaign. The FLEXPART model simulations have been driven by operational meteorological input data of the European Centre for Medium-Range Weather Forecasts $\left(\right.$ ECMWF) with $0.2^{\circ} \times 0.2^{\circ}$ spatial resolution (derived from T799 spectral truncation). The model domain extends from $20^{\circ} \mathrm{W}$ to $70^{\circ} \mathrm{E}$ and 20 to $70^{\circ} \mathrm{N}$ covering Europe, northern Africa and western Asia. To provide a temporal resolution of $1 \mathrm{~h}$ a combination of analyses at 00:00, 06:00, 12:00 and 18:00 UTC and short-forecast data at intermediate time steps was used. Backward simulations were started from the measurement point in the northwest of Cyprus by releasing 10000 neutral inert air tracer particles during an $1 \mathrm{~h}$ time interval which are followed as trajectories over 5 days.

The positions of the tracer particles are calculated on a 3-D grid with a horizontal resolution of $0.2^{\circ}$ that corresponds to the resolution of the input data on the model domain. A vertical resolution of 58 layers is used extending from $100 \mathrm{~m}$ (minimum height of the planetary boundary layer (PBL) set in the model) to an altitude of $10000 \mathrm{~m}$. The height of the layers gradually increases from 20 to $1000 \mathrm{~m}$. The temporal resolution corresponds to the input data and is available in hourly time steps within the simulation period of $120 \mathrm{~h}$. In total, 216 simulations covering 9 July 2014, 00:00 UTC, to 4 August 2014, 21:00 UTC, in $3 \mathrm{~h}$ time steps were carried out. They cover the entire period of the measurement campaign.

The output of FLEXPART is a 4-D function of emission sensitivity (Stohl et al., 2007a), three spatial dimensions plus time, derived from the positions of all trajectories. It describes the relation between any emission source that is passed by the trajectories and the concentration of the respective atmospheric substance at the receptor. Since atmospheric emissions are diluted by mixing in adjacent air, emission sources are specified as emitted mass per time and volume in units of $\mathrm{kg} \mathrm{m}^{-3} \mathrm{~s}^{-1}$, denoted by $q$. Receptor concentrations are expressed in a conservative quantity as mass mixing ratios, specified by $\chi$ (unitless). Then, the emission sensitivity is determined by the sum of the residence time $T$ of all trajectories in this adjacent volume of air divided by the local air density $\rho$ in $\mathrm{kg} \mathrm{m}^{-3}$ without transmission correction (Seibert and Frank, 2004):

$\frac{\partial \chi}{\partial q_{i j k n}}=\frac{T_{i j k n}}{\rho_{i j k n}}$.

It is computed in the predefined 3-D output grid that uses the indices $i, j, k$ to specify the spatial position $x_{i}, y_{j}, z_{k}$ in the centre of each grid box. The fourth index $n$ determines the time step $t_{n}$ within the simulation period. This emission sensitivity can be interpreted as a source-weight factor. It de- scribes the source contribution to the mass mixing ratio at the receptor relative to the source strength when any transport losses are ignored.

In addition to the described standard output, FLEXPART provides the PBL height for all individual tracer particles at their geographical position at each time step. The PBL heights are calculated by the model according to Vogelezang and Holtslag (1996) and use the concept of the critical Richardson number, which is based on surface sensible heat fluxes and surface stresses available from the ECMWF input data (Sect. 3 in Stohl et al., 2005).

\subsection{Surface emission sensitivity}

Since we are interested in area sources at ground level, the emission sensitivity for volume sources in Eq. (1) is slightly modified to derive the sensitivity to surface emissions. The emission flux of an area source $q_{\mathrm{A}}$ is diluted over a vertical layer adjacent to the ground, the FL of height $h$, following $q=q_{\mathrm{A}} h^{-1}$. With this assumption, all grid boxes of height $z_{k} \leq h_{i j n}$ are attributed to the mixing volume in the FL height and influenced by pollutants. Here we use a variable FL height $h_{i j n}$ in space and time that is specified by the corresponding indices $i, j, n$. Then, the emission sensitivity $S$ to surface area sources in units of $\mathrm{s} \mathrm{m}^{2} \mathrm{~kg}^{-1}$ is obtained with the density-weighted residence time $\widehat{T}_{i j n}$ in this mixing volume as

$$
\begin{aligned}
\widehat{T}_{i j n} & =\sum_{k=1}^{z_{k} \leq h_{i j n}} \frac{T_{i j k n}}{\rho_{i j k n}}, \\
S_{i j n} & =\frac{\widehat{T}_{i j n}}{h_{i j n}} .
\end{aligned}
$$

In this study, we use different FL heights and have implemented three methods:

- The first method uses the assumption of a constant FL height. Here, we choose a layer of $h=300 \mathrm{~m}$, which is used in published studies. Additionally, this height is slightly above the PBL minimum in the model of $100 \mathrm{~m}$. This allows analysis of the case that the assumed FL height exceeds the PBL height.

- The second method is new in this study and uses a FL height $h_{i j n}$ that is variable in space and time. With this dynamic FL height assumption, the emission sensitivity depends on locally varying FL heights. We use local PBL heights calculated by the FLEXPART model to implement this dynamic FL height. However, from the output of FLEXPART only PBL heights along the particles' trajectories are available. To obtain gridded PBL heights from all single particle positions, we adapt the methodology described in Stohl et al. (2005), Sect. 8.1. We modify their Eq. (50) and calculate the PBL height $h$ on the spatio-temporal output grid 
Table 1. Subdivision of the difference in emission sensitivity $\Delta S$ caused by FL height variations $\Delta h$ assigned to their dominating effects.

\begin{tabular}{ll}
\hline Cases of interaction & Dominating effect \\
\hline$\Delta h>0$ and $\Delta S<0$ & $\left|\frac{\Delta \widehat{T}}{\widehat{T}}\right|<\left|\frac{\Delta h}{h}\right|$ loss in concentration (stronger dilution) \\
$\Delta h>0$ and $\Delta S>0$ & $\left|\frac{\Delta \widehat{T}}{\widehat{T}}\right|>\left|\frac{\Delta h}{h}\right|$ gain in impact \\
$\Delta h<0$ and $\Delta S>0$ & $\left|\frac{\Delta \widehat{T}}{\widehat{T}}\right|<\left|\frac{\Delta h}{h}\right|$ gain in concentration (less dilution) \\
$\Delta h<0$ and $\Delta S<0$ & $\left|\frac{\Delta \widehat{T}}{T}\right|>\left|\frac{\Delta h}{h}\right|$ loss in impact \\
\hline
\end{tabular}

$h=\sum_{p=1}^{N}\left(f_{p} h_{p}\right)$

with $N$ being the total number of particles, $h_{p}$ the PBL height of particle $p$ and $f_{p}$ the fraction of the particle attributed to the respective grid cell. To calculate this fraction, we use a uniform kernel with bandwidths of $0.2^{\circ}$ that corresponds to the output grid.

- The third method is specifically developed for the application on fire emissions. It is based on the plume rise model (PRM) injection heights from the Global Fire Assimilation System (GFAS) (Rémy et al., 2017; Paugam et al., 2015). These fire-observation-based plume heights are used as a variable FL height to simulate the emission impact of fire emissions provided by the GFAS (Kaiser et al., 2012).

\subsection{Analysing the impact of FL height assumptions}

To analyse the impact of FL height variations, we calculate the emission sensitivity for constant and dynamic FL heights and analyse their differences. The absolute difference is described by

$\Delta S_{i j n}=S_{i j n}\left(h_{i j n}\right)-S_{i j n}(h)$.

Here, $\Delta S_{i j n}$ is defined such that it is positive when FL height differences introduce a higher emission sensitivity compared to the constant $300 \mathrm{~m}$ FL height assumption. Differences in FL height are determined in the same way, $\Delta h_{i j n}=h_{i j n}-h$, with positive sign for an increase.

To analyse the changes in emission sensitivity that are introduced by varying FL heights, Eq. (3) is differentiated with respect to $h$,

$$
\frac{\mathrm{d} S(h)}{\mathrm{d} h}=\frac{\widehat{T}}{h} \frac{1}{\mathrm{~d} h}\left(\frac{\mathrm{d} \widehat{T}}{\widehat{T}}-\frac{\mathrm{d} h}{h}\right) .
$$

Discretising the differentials results in the simple relation

$$
\frac{\Delta S}{S}=\frac{\Delta \widehat{T}}{\widehat{T}}-\frac{\Delta h}{h} .
$$

The relative change in density-weighted residence time $\left|\frac{\Delta \widehat{T}}{\widehat{T}}\right|$ describes the gain/loss in impact since a deeper FL height can capture more trajectories. The second term describes the relative change in FL height $\left|\frac{\Delta h}{h}\right|$. It quantifies the dilution of emitted substances and represents the gain/loss in concentration. Thus, to describe the relative change in emission sensitivity, we need to analyse the overall difference of both effects. Additionally, both effects are coupled and interact with each other. An increase in FL height results in an increase in residence time and is accompanied by a stronger dilution. Hence, the changes in emission sensitivity are the result of the counteracting effects: gain in impact and loss in concentration (dilution effect). It is crucial to know which of the two turns out to be the dominating effect. This interaction is described in a case-by-case analysis presented in Table 1 for increasing and decreasing FL heights, respectively.

Following this case-by-case analysis, the overall difference in emission sensitivity, spatially and/or temporally integrated, is the result of the following four characteristic differences:

$$
\begin{aligned}
\underbrace{\Delta S_{\text {tot }}}_{\text {overall difference }}= & \underbrace{\Delta S^{-}\left(\Delta h^{+}\right)}_{\text {dilution effect }<0}+\underbrace{\Delta S^{+}\left(\Delta h^{+}\right)}_{\text {gain in impact }>0} \\
& +\underbrace{\Delta S^{+}\left(\Delta h^{-}\right)}_{\text {gain in concentration }>0}+\underbrace{\Delta S^{-}\left(\Delta h^{-}\right)}_{\text {loss in impact }<0} .
\end{aligned}
$$

Here, $\Delta S^{ \pm}$respectively $\Delta h^{ \pm}$are defined according to

$\Delta X^{+}= \begin{cases}\Delta X, & \Delta X>0 \\ 0, & \Delta X<0\end{cases}$

and

$\Delta X^{-}= \begin{cases}0, & \Delta X>0 \\ \Delta X, & \Delta X<0 .\end{cases}$

The contributions interfere with each other and can buffer the overall difference. However, the individual contributions account for the variability that is introduced by changes in FL heights. The negative and positive contributions span up a margin that envelopes the overall difference. A narrow or vanishing margin indicates a balance of the counteracting effects and little impact on the emission sensitivity. Therefore, 
this margin is a simplified tool to quantify the potential of errors in source analysis induced by a FL height assumption and uncertainties in the representation of vertical mixing.

\subsection{Simulation of $\mathrm{CO}$ source contributions}

The fields of emission sensitivity $S_{i j n}$ on the spatio-temporal output grid (spatial indices: $i, j$; temporal index: $n$ ) derived from the FLEXPART simulations have been calculated for inert substances. Therefore, the emission sensitivity quantifies the relative source contribution from any emitted species that are conserved on timescales used here, such as carbon monoxide. To derive the absolute source contribution from $\mathrm{CO}$ emission sources, we need an additional field of $\mathrm{CO}$ emission mass flux density on the spatio-temporal grid, $q_{i j n}^{\mathrm{CO}}$ in $\mathrm{kg} \mathrm{s}^{-1} \mathrm{~m}^{-2}$. Folding the sensitivity with the emission flux density and temporal integration results in a new field of potential CO source contributions

$\chi_{i j}^{\mathrm{CO}}(t)=\sum_{n}\left(S_{i j n}(t) \cdot q_{i j n}^{\mathrm{CO}}\right)$.

$\chi_{i j}^{\mathrm{CO}}$ is a unitless quantity and describes the $\mathrm{CO}$ contribution from the respective grid cell to the measured $\mathrm{CO}$ mass mixing ratio at the receptor point at time $t$. Therefore, it is used to identify the geographical distribution of sources and their impact. In general, a strong impact is expected if enhanced emission sensitivity encounters a strong emission flux. However, if errors in calculated emission sensitivities encounter strong local emission sources, the error in source contributions is expected to increase.

Spatial integration finally results in the total mass mixing ratio that is transported to the receptor. It represents the $\mathrm{CO}$ contribution due to transport process and should be quantitatively comparable to the measured enhancement over the typical background concentration $\chi_{0}$ (Seibert and Frank, 2004; Stohl et al., 2007a). The observed CO mass mixing ratio $\chi_{\text {obs }}$ at the receptor at time $t$ is thus the sum of the background mass mixing ratio and the transport contribution

$\chi_{\mathrm{obs}}(t)=\chi_{0}+\sum_{i, j} \sum_{n}\left(S_{i j n}(t) \cdot q_{i j n}^{\mathrm{CO}}\right)+\epsilon$.

The uncertainty $\epsilon$ accounts for older $\mathrm{CO}$ contributions prior to the simulation period, for unknown $\mathrm{CO}$ sources and model errors such as neglected transport losses.

In this study, we use the Global Fire Assimilation System GFAS1.2 (Kaiser et al., 2012) to quantify the CO source contributions from biomass burning of forest fires to the $\mathrm{CO}$ concentration at Cyprus during the CYPHEX campaign. We explicitly use the corresponding fire-observation-based altitude of plume top (Rémy et al., 2017) to derive a dynamical FL height that accounts for pyroconvection in the fire spots. The $\mathrm{CO}$ source contributions are calculated for this dynamical FL height and a constant FL height of $300 \mathrm{~m}$. Additionally, the CO contributions for the $100 \mathrm{~m}$ FL height and the PBL height are considered for an extended comparison.

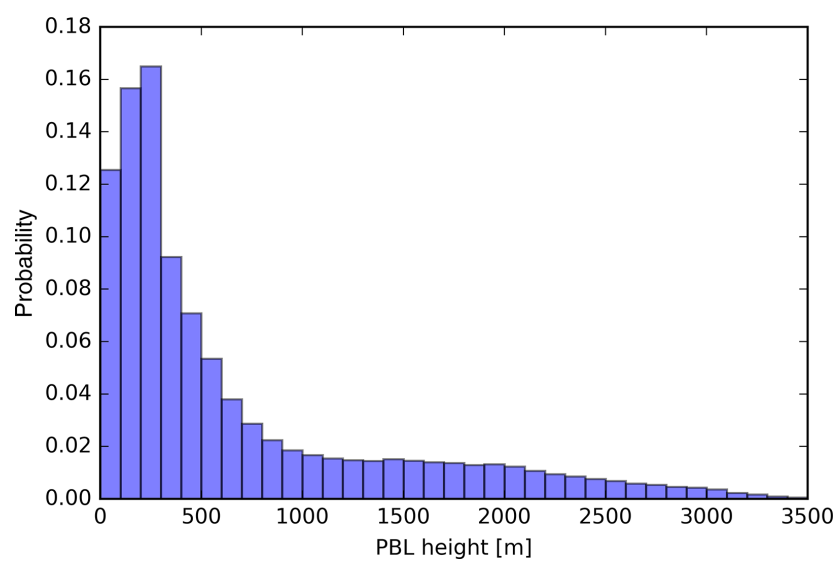

Figure 1. Frequency distribution of PBL heights occurring during the 5-day backward simulation from 19 July 2014, 00:00 UTC (03:00 LT).

However, in the period of the campaign, fire intensity was too weak to influence the $\mathrm{CO}$ concentration significantly. To analyse the impact of errors in calculated emission sensitivities, a strong fire event is necessary. Thus, we use a 5-day $\mathrm{CO}$ emission pattern of a large biomass burning event that occurred in Greece on 24-28 August 2007. During this period Greece suffered the worst forest fires in the past 50 years (Poupkou et al., 2014).

\section{Results}

\subsection{Differences in emission sensitivity}

\subsubsection{A single case study}

First we analyse the impact of FL height variations in a case study of the 19 July 2014, 00:00 UTC (03:00 LT). This case study describes the transport of air masses from southeastern Europe to Cyprus on a continental transport route during the five previous days. For transport routes along land masses, we can expect a pronounced diurnal cycle in PBL heights with peaks during daytime up to $2-3 \mathrm{~km}$ and the lowest layers about 100-300 $\mathrm{m}$ at night. This variability in PBL heights during 5 days of transport time is analysed in a frequency distribution in Fig. 1. PBL heights above $300 \mathrm{~m}$ are assumed to represent well-mixed convective PBL heights, while heights below $300 \mathrm{~m}$ are characterised by less vertical mixing in more stable conditions. A minimum vertical mixing, however, is assumed within the PBL minimum of $100 \mathrm{~m}$ set in the model. The probability for the occurrence of a PBL height within $300 \mathrm{~m}$ is about $45 \%$. Constant FL height assumptions in this range can compensate for an underrepresentation of vertical mixing in the trajectories. In total, $55 \%$ of PBL heights exceed $300 \mathrm{~m}$, which can influence the emission sensitivity, so that the analysis depends on a realistic representation of vertical mixing in the trajectories. 

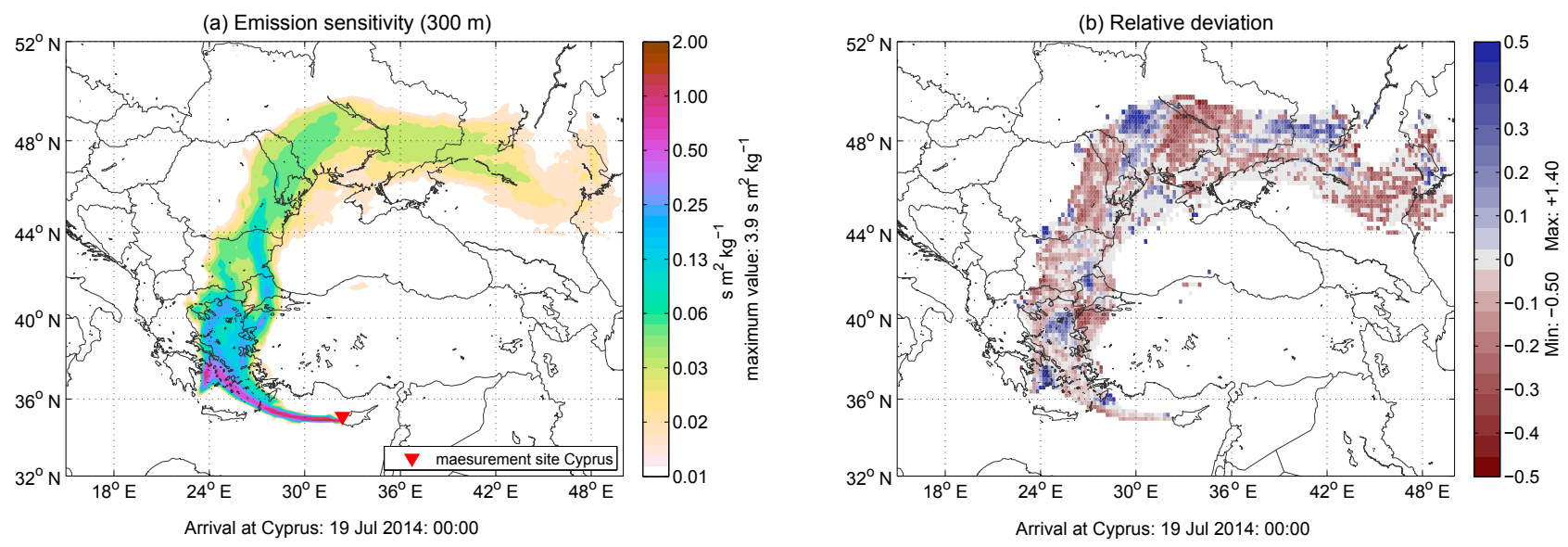

Figure 2. (a) Time integrated emission sensitivity referring to the constant $300 \mathrm{~m}$ footprint layer height assumption for a 5-day backward simulation started on 19 July 2014, 00:00 UTC (03:00 LT), at Cyprus. Sensitivities below $0.01 \mathrm{~s} \mathrm{~m}^{-2} \mathrm{~kg}^{-1}$ are not considered. (b) Relative difference in emission sensitivity introduced by differences between local boundary layer heights and the constant $300 \mathrm{~m}$ footprint layer height. Only absolute sensitivity differences above $0.0025 \mathrm{~s} \mathrm{~m}^{-2} \mathrm{~kg}^{-1}$ are used to calculate relative differences.

(a) Emission sensitivity

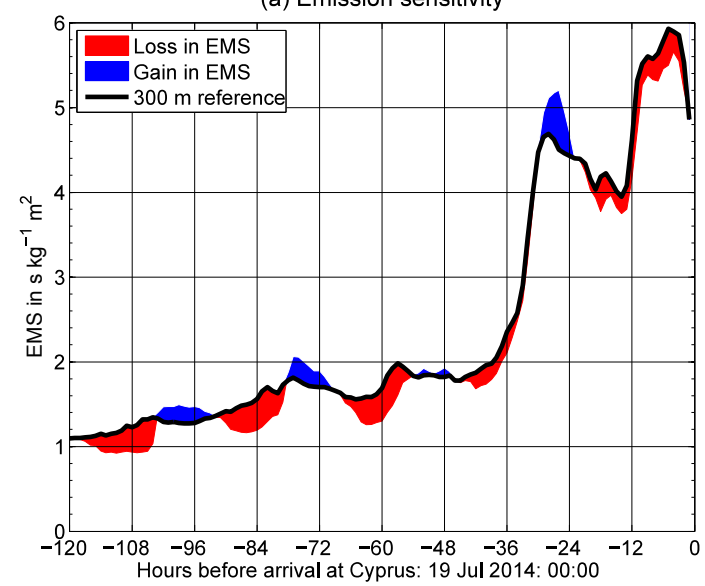

(b) Density-weighted residence time

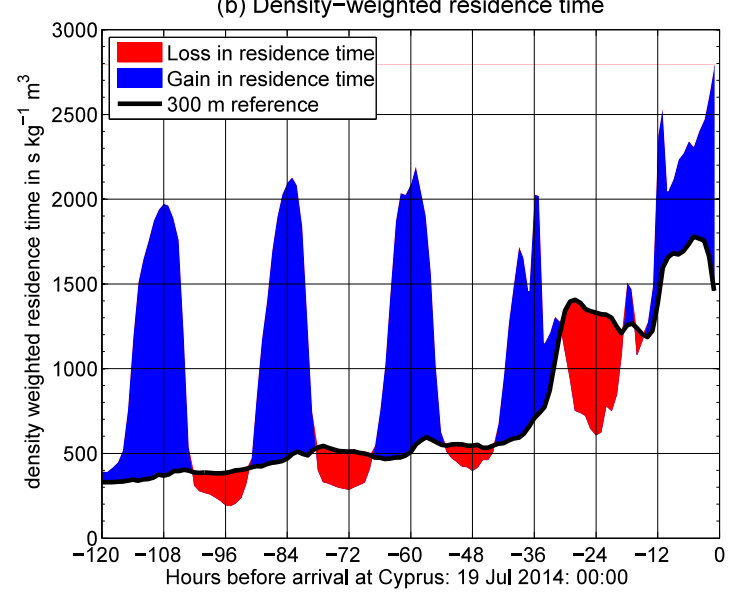

Figure 3. (a) Time series of spatially integrated emission sensitivity (EMS) based on variable boundary layer heights with positive differences (blue areas) and negative (red areas) in reference to the $300 \mathrm{~m}$ assumption (black line). (b) Spatially integrated density-weighted residence time of boundary layer heights with differences shown by filled areas with respect to the $300 \mathrm{~m}$ layer.

As a starting point, we analyse the emission sensitivity for the constant $300 \mathrm{~m}$ FL height. By using a constant FL height, the emission sensitivity only depends on the changes in the (density-weighted) residence time since the dilution of emission flux is constant. Therefore, we integrate the emission sensitivity $S_{i j n}$, following Eq. (3), in time. The resulting 2$\mathrm{D}$ field is mapped as shown in Fig. 2a and indicates regions of enhanced sensitivity by colours. The higher the sensitivity values the higher the contribution of a source area. This method is typically used in LPDM applications to localise hotspots of upwind emission sources and to quantify their impact on the measurement site. For this standard application, we compare the emission sensitivities for the $300 \mathrm{~m} \mathrm{FL}$ height and local varying FL heights realised by PBL heights. Following Eq. (7), the difference $\Delta S_{i j n}$ depends on the com- bined effect of changes in (density-weighted) residence time and in the dilution of emission flux. According to the $300 \mathrm{~m}$ standard application, we integrate $\Delta S_{i j n}$ in time. Since $\Delta S_{i j n}$ can be positive and negative over the course of the day, confer Table 1, the obtained 2-D field represents the net effect during the 5-day simulation period. It is shown in Fig. 2b and indicates the relative differences in emission sensitivity compared to Fig. 2a.

In this example, the spatial distribution exhibits a pattern of positive and negative values. Thus, the application of the constant $300 \mathrm{~m}$ FL height causes both an over and an underestimation of emission sensitivity compared to local PBL heights. However, the time-integrated differences represent the net effect over 5 days. In fact, the differences at single time steps can be larger. Here, the "fixed" FL height applica- 
tion capitalises on over- and underestimations compensating for each other. The remaining net effect reveals an alternating spatial pattern. This is linked to the diurnal cycle of the PBL height since the trajectories pass distinct regions preferred at day or night-time.

Therefore, we explore the impact of temporal variations in FL height respective PBL heights and spatially integrate the emission sensitivity. Then, it only depends on time and its evolution can be represented in a simple time series over the simulation period. For a comparison, this time series is calculated for the emission sensitivity of the constant $300 \mathrm{~m} \mathrm{FL}$ height and local PBL heights as shown in Fig. 3a. The colour of the filled areas indicates the sign of the difference and represents a regular alternating pattern. This results from the characteristics of a diurnal cycle that leads to a pronounced temporal dependency. During daytime, the changes in PBL height introduce a loss in emission sensitivity and a gain over night. This suggests that stronger dilution in daytime FL heights reduces the emission sensitivity, even though more trajectories are influenced by emissions. To further analyse this effect, the density-weighted residence time $\widehat{T}$ (Eq. 2) of all trajectories within the FL height is integrated in time. The time series is shown in Fig. 3b for the constant $300 \mathrm{~m} \mathrm{FL}$ height and the varying PBL height with differences identified by colours. The different colours indicate a strong gain in residence time during daytime and a loss at night that correlates with the diurnal cycle of PBL heights. Furthermore, the comparison of both time series in Fig. 3 points out that the gain in residence time over day is linked to a loss in emission sensitivity. Consequently, the dilution compensates for the gain in impact and vice versa. Averaged over the whole time period, the loss in emission sensitivity dominates by $-4 \%$. However, this mean value covers smaller positive differences that occur at night time.

To account for the local and temporal variability in more detail, the overall difference is subdivided in contributions of the individual effects following Eq. (8) and Table 1. Theoretically, when PBL heights exceed the constant $300 \mathrm{~m}$ FL height assumption, the emission sensitivity can either decrease or increase. In this example, the stronger dilution predominately compensates for the gain in impact over the whole period. This effect contributes by $-8.8 \%$ to the overall difference in emission sensitivity. However, in a few cases the dilution effect is less dominant and the gain in impact causes a positive contribution of $2.2 \%$. When the PBL heights fall below $300 \mathrm{~m}$, the described effects are reversed. Then, an increase in emission sensitivity by $6.2 \%$ is observed due to the intensified concentration in shallow FL heights. However, when the loss in impact is stronger than this concentration effect, the emission sensitivity decreases. This effect contributes by $-3.6 \%$ to the overall difference.

By merging these four separated effects, a margin between -12.4 and $+8.4 \%$ is spanned. This margin envelopes the mean difference in emission sensitivity of $-4 \%$ and represents the effects of local and temporal variability. Therefore,
FL height changes within the PBL height are not buffered and result in over and underestimations in source contributions compared to a constant $300 \mathrm{~m}$ FL height assumption.

\subsubsection{Analysing the whole set of case studies}

The analysed case study is only representative of a specific synoptic situation. We extend the analysis on the whole available set of 216 cases studies to account for a variety of synoptic situations. Typically in summertime, a dominant pattern of northerly winds is expected in the eastern Mediterranean that drives the transport of continental air masses from eastern Europe. However, four distinct periods of west and southwesterly flow in the eastern Mediterranean were observed in July 2014 that cut off the expected continental transport routes and brought maritime air to Cyprus (Tyrlis et al., 2015). These unseasonal wind patterns offer a wide variety of synoptic situations. The analysis for the whole set of case studies is therefore not only representative of typical summertime conditions.

To compare different case studies, the procedure of the previous section, following Eq. (8), is applied. For each case study, the overall and the margin of individual differences in emission sensitivity is calculated. The results are shown in a time series over the period of the CYPHEX campaign in Fig. 4. Here, the individual contributions are specified by different colours and envelop the overall difference as an uncertainty margin. By representing the temporal evolution over the time period of a month, changes on the temporal scale of days and weeks are involved. Therefore, this overview accounts for the impact of different synoptic patterns.

At first sight, it is obvious that negative differences dominate with mean values around $-5 \%$. However, the wide margin points out that the variability allows for differences of $10 \%$ and even more in both directions. For a detailed discussion, the differences are calculated as a mean over all 216 simulations combined with the interquartile range. The results are summarised in a box-and-whisker plot in Fig. 5 and corresponding values of mean values, box and whisker ranges listed in Table 2 . The box-and-whisker plot represents the spreading of data points and can be used to quantify the impact of each effect. Additionally, it accounts for the variability and includes single outliers that occur in changing synoptic conditions.

The detailed analysis of all case studies shows that the use of a variable FL height within the PBL lowers the emission impact. During summer at Cyprus, the $300 \mathrm{~m}$ FL height assumption predominately overestimates the emission sensitivity. For most simulations, the FL height differences introduce an overall mean difference in emission sensitivity between -2.8 and $-7.4 \%$. This negative effect is mainly driven by the neglected dilution in PBL heights that frequently exceed the $300 \mathrm{~m}$ footprint height assumption. For the majority of case studies, the dilution effect dominates the gain in impact and contributes negatively, by $6-11 \%$, to the mean overall 


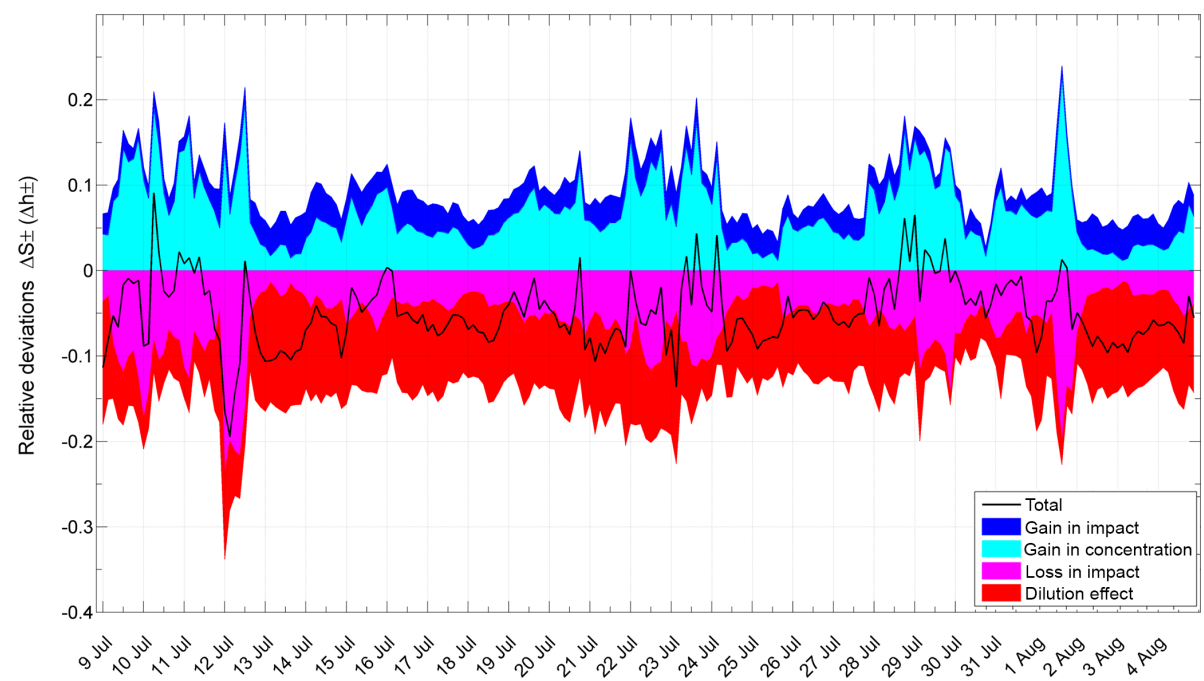

Figure 4. Temporal changes in the overall difference in emission sensitivity $\Delta S_{\text {tot }}$ enveloped by the positive and negative contributions that correspond to increase/decrease in footprint layer height $\Delta h \pm$ and the defined effects of Eq. (8) based on 216 simulations. Differences by footprint layer variations are calculated relatively in reference to the constant $300 \mathrm{~m}$ assumption.

Table 2. Mean values and calculated intervals in per cent for the interquartile range and the 2nd to 98th percentile as shown in the box-andwhisker plot in Fig. 5.

\begin{tabular}{lrrr}
\hline Effect & Mean & $25-75 \%$ box range & 2-98\% whisker range \\
\hline Dilution & -8.5 & {$[-10.6,-6.1]$} & {$[-14.1,-2.7]$} \\
Gain in impact & +2.6 & {$[+2.0,+3.2]$} & {$[+1.0,+4.4]$} \\
Loss in impact & -6.1 & {$[-7.5,-3.6]$} & {$[-19.9,-1.5]$} \\
Gain in concentration & +6.9 & {$[+4.1,+8.9]$} & {$[+1.5,+16.7]$} \\
Overall & -5.0 & {$[-7.4,-2.8]$} & {$[-11.8,+4.2]$} \\
\hline
\end{tabular}

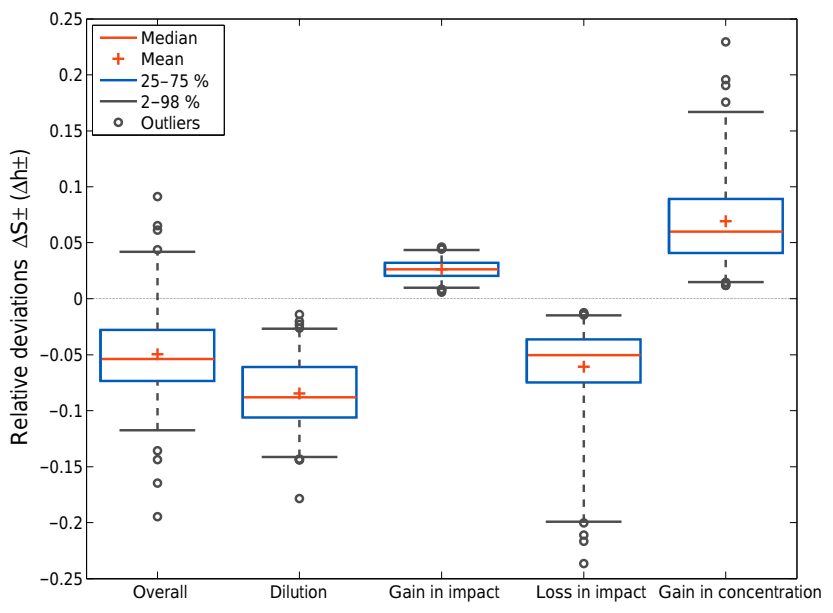

Figure 5. Box-and-whisker plot for the overall differences in emission sensitivity and the contributions of the different effects in reference to the $300 \mathrm{~m}$ assumption based on 216 simulations. The whisker ends are defined by the 2nd and 98th percentile and the remaining outliers are considered by outlying circles.
Table 3. Total CO contributions for different footprint layer heights and relative differences in reference to the results of fire plume top heights.

\begin{tabular}{lrr}
\hline Footprint height & CO contribution & Relative difference \\
\hline $100 \mathrm{~m}$ & $745 \mathrm{ppb}$ & $+77 \%$ \\
$300 \mathrm{~m}$ & $676 \mathrm{ppb}$ & $+60 \%$ \\
PBL & $555 \mathrm{ppb}$ & $+32 \%$ \\
Fire plume height & $420 \mathrm{ppb}$ & - \\
\hline
\end{tabular}

difference. However, this changes when air tracers agglomerate above the standard $300 \mathrm{~m}$ footprint height and thereby are captured by the overlying PBL height. Then, the gain in impact dominates and leads to an increase in emission sensitivity of about $2-3 \%$.

When PBL heights fall below $300 \mathrm{~m}$, the concentration of emitted mass flux is intensified and fewer trajectories are captured by the shallower layer. This gain in concentration counteracts the decreasing residence time and contributes by $4-9 \%$ to the difference in emission sensitivity. However, this is reversed when the air tracers agglomerate between 

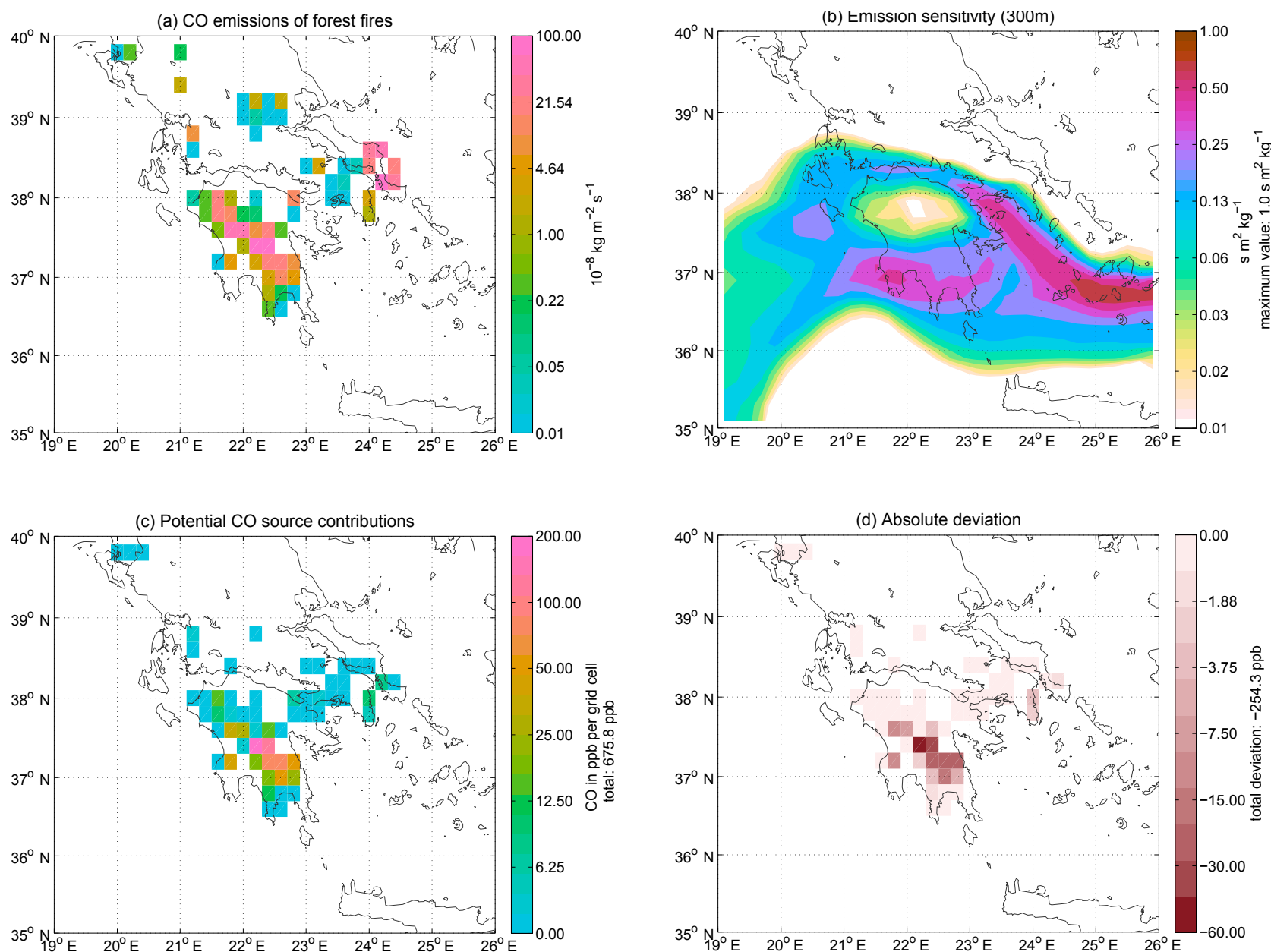

Figure 6. (a) CO emissions for forest fires in Greece on 26 August 2007 provided by GFASv1.2 (Kaiser et al., 2012) and aggregated on a grid of $0.2^{\circ}$. (b) Time-integrated emission sensitivity of a 5-day backward simulation from 30 July 2014, 15:00 UTC (03:00 LT), started at Cyprus and based on the $300 \mathrm{~m}$ footprint layer height. (c) CO source contributions of forest fires to mass mixing ratio at Cyprus assuming a $300 \mathrm{~m}$ footprint layer height and (d) absolute differences introduced by using variable fire plume heights as footprint layer height.

(a) CO source contributions

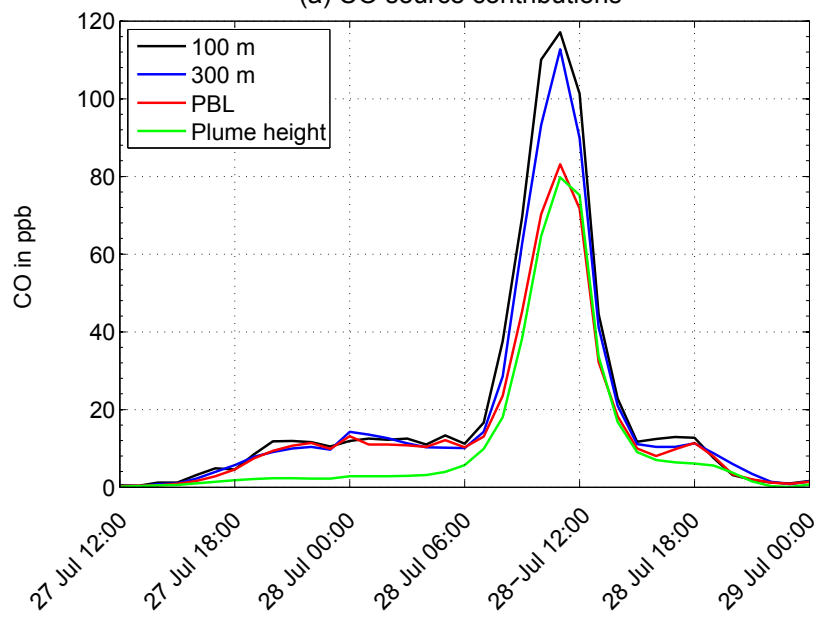

(b) Density-weighted residence time

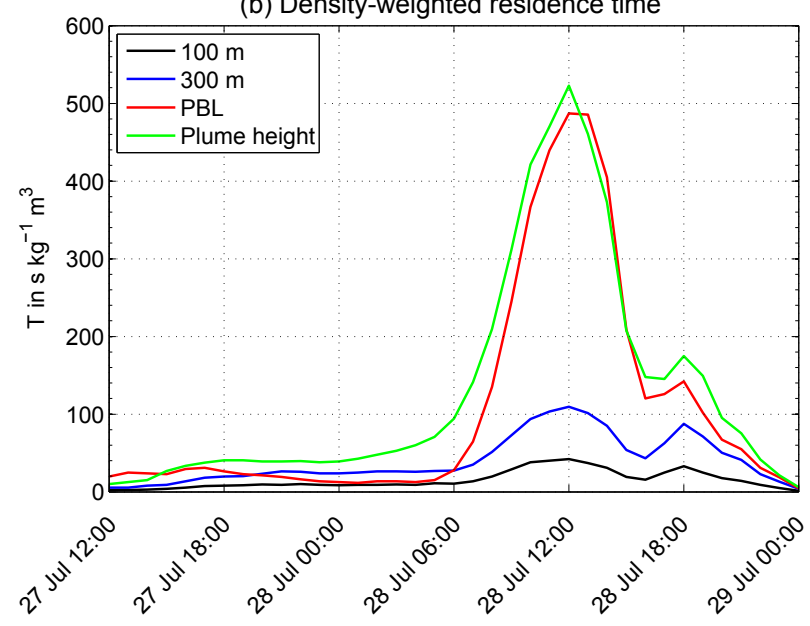

Figure 7. (a) Time series of spatial integrated CO source contributions for the different footprint layer heights and (b) the corresponding series of density-weighted residence time for the time window when Greek forest fires were passed. 
100 and $300 \mathrm{~m}$ height above a shallow PBL height of about $100 \mathrm{~m}$. Such conditions typically occur when hot continental air masses reach the relatively cooler sea surface and travel slightly above the shallow marine PBL height. Then, the air tracers are captured by the $300 \mathrm{~m}$ FL height assumption, even though they are in the free troposphere. According to this, a lower FL height decreases the emission sensitivity due to a loss in impact. This negative effect contributes about 4-8\%. However, the strong outliers of up to $-20 \%$ represent a pronounced variability of this difference. This variability emphasises the risk of a false identification of emission sources within the constant $300 \mathrm{~m}$ FL height.

Overall, a negative difference in emission sensitivity is observed. However, 21 positive outliers with a maximum of $9 \%$ were found among the 216 simulations and the 98th percentile represents a positive difference of $+4.2 \%$. This variability limits a distinct statement regarding the sign of errors that is introduced by FL height variations. Hence, the $300 \mathrm{~m}$ FL height assumption can over and underestimate the impact of emission sources depending on local PBL heights and meteorological conditions.

\subsection{Differences in source contributions}

\subsubsection{Application - simulation of extreme, localised CO source contributions}

In this section, we analyse the impact of specific emission sources. This impact depends on the emission sensitivity and, additionally, on the local distribution and source strength of pollutants.

We calculate the $\mathrm{CO}$ source contributions from forest fires as described in Sect. 2.4 for the $300 \mathrm{~m}$ FL height and for the specific fire plume top heights. During August 2007 strong forest fires occurred in Greece with the highest $\mathrm{CO}$ emissions on the 26 August as shown in Fig. 6a. We combine the 5-day period from 24 to 28 August 2007 with the simulation of 26-30 July 2014 that shows transport routes passing through the fire regions. This is indicated in the corresponding map of temporal integrated emission sensitivities based on the constant $300 \mathrm{~m}$ FL height in Fig. 6b. Hence, uptake of $\mathrm{CO}$ emissions and impact at the receptor can be expected in this hypothetical case.

The spatial distribution of $\mathrm{CO}$ source contributions is calculated following Eq. (11) and shown in Fig. 6c. In total, the Greek forest fires cause a CO contribution of $676 \mathrm{ppb}$ in the simulation. This is an order of magnitude larger than typical background $\mathrm{CO}$ values at Cyprus of approximately $70 \mathrm{ppb}$ which is the minimal value measured during the CYPHEX campaign (Uwe Parchatka, personal communication, 2015) in unpolluted air. Nevertheless, the $\mathrm{CO}$ enhancement is a realistic value for this extreme fire event in Greece 2007. Poupkou et al. (2014) show similar enhancements in their model simulations for this specific fire event.
For these extreme fires the emission heights significantly exceed the $300 \mathrm{~m}$ FL height. On the 26 August 2007, the altitude of fire plume top is between 1 and $3 \mathrm{~km}$ and is used to represent the FL height. We also calculate the CO source contributions that result from the fire plume heights. The absolute differences compared to the $300 \mathrm{~m}$ FL height are integrated in time and the spatial distribution is represented in Fig. $6 \mathrm{~d}$ by different colours. Since only negative values are found over Greece, the FL height variations cause an overestimation of the $\mathrm{CO}$ concentration at the receptor. This overestimation sums up to a total difference of $-254 \mathrm{ppb}$ or $60 \%$ compared to the simulated CO contribution of $422 \mathrm{ppb}$ for fire plume top heights. Accordingly, the stronger dilution in the deeper fire plume height is the major effect and dominates the gain impact in this hypothetical height.

For a more detailed analysis we spatially integrate the 3$\mathrm{D}$ field of CO source contributions. Then, the total uptake of $\mathrm{CO}$ at each time step can be shown in a time series. Additionally, we also calculate the source contributions for the $100 \mathrm{~m}$ FL height and the dynamical layer that follows local PBL heights. In Fig. 7a, the uptake of CO contributions is shown for the time window when the Greek forest fires would have been passed by the trajectories. It reveals that the major uptake takes place over day between 06:00 and 15:00 UTC. The comparison between different FL height assumptions indicates similar CO values for the constant 100 and $300 \mathrm{~m} \mathrm{FL}$ height. They significantly exceed the values for the dynamical layers of the PBL and the fire plume top height.

At the peak of CO uptake at 11:00 UTC on 28 July, the CO contributions of the fire plume height and the PBL height are about $30 \%$ below the level of the 100 or $300 \mathrm{~m}$ FL height. This is basically caused by the strong dilution of emitted $\mathrm{CO}$ in the deep layer of the fire plume respective PBL height. Both layers are about $1700 \mathrm{~m}$ with slightly higher values for the fire plume height. At night-time, the PBL heights are in the range of the fixed FL heights and the simulated $\mathrm{CO}$ source contributions are similar. We also analyse the time series of the density-weighted residence time $\widehat{T}$. In Fig. $7 \mathrm{~b}$, it is arranged next to the time series of $\mathrm{CO}$ contributions. It confirms that the residence time increases for deeper FL heights with the highest values for the fire plume and PBL height. However, this pronounced gain in impact is not sufficient to compensate for the strong dilution, which results in lower $\mathrm{CO}$ contributions for both dynamical FL heights. In contrast to that, the $300 \mathrm{~m}$ simulation shows only a small gain in impact compared to the $100 \mathrm{~m}$ FL height that is almost compensated for by the stronger dilution. Both constant FL heights have similar CO contributions of 676 and $745 \mathrm{ppb}$.

Overall, the $100 \mathrm{~m}$ FL height results in the highest CO contributions that exceeds the contribution from fire plume heights by $77 \%$. The $300 \mathrm{~m}$ FL height yields $60 \%$ and the PBL height $32 \%$ more $\mathrm{CO}$ (see Table 3 ). Therefore, constant FL heights of 100-300 m significantly overestimate the emission impact in this meteorological situation. 


\section{Conclusions}

In this study, we analysed the impact of different footprint layer (FL) height assumptions on the quantification of source contributions with the Lagrangian particle dispersion model (LPDM) FLEXPART. The FL height defines the vertical layer adjacent to the ground in which surface emissions are present and assumed to affect passing air tracer particles. Consequently, the assumed FL height determines a dilution of any emitted pollutants and the number of trajectories exposed to the emissions. Both effects counteract each other: a growth in FL height leads to a stronger dilution that is coupled to a stronger impact. In a well-mixed layer with a homogeneous trajectory distribution and thus a constant tracer particle density, the counteracting effects are balanced. The dilution is in addition to the vertical mixing represented in the underlying meteorological model. It thus has the potential to compensate for any underestimation of vertical mixing in the trajectories. Then, FL height variations are buffered and the results of source quantification are independent of the FL height. Pan et al. (2014) found that FL height changes up to $300 \mathrm{~m}$ had no effect on the results. In fact, constant FL heights between 100 and $300 \mathrm{~m}$ are used in most LPDM applications. However, mixing processes in the planetary boundary layer (PBL) have a pronounced spatio-temporal variability. Pollutants can be vertically diluted on timescales about $15 \mathrm{~min}$ within heights up to $2-3 \mathrm{~km}$. In these cases the PBL is well mixed and its height can be used as a reference FL height that is independent of the vertical mixing represented by the trajectories. We explicitly use the local PBL heights as a dynamical FL height and compare the results to a constant FL height of $300 \mathrm{~m}$.

For the comparison, we used in total 216 FLEXPART simulations that were carried out during the CYPHEX campaign at Cyprus in July 2014. The case studies provide different meteorological conditions and transport patterns. For convective conditions over day, the PBL heights significantly exceed the $300 \mathrm{~m}$ FL height assumption. Here, the increase in FL heights causes a decrease in source contributions by $6 \%$ on average. The variability of local conditions even allows for a decrease of more than $10 \%$. The vertical mixing appears to be underrepresented in the trajectories and the technique of the fixed FL height assumption introduces an error. The overestimation of source contributions points out that Cyprus has a large impact from trajectories at lower levels. More trajectories at levels above $300 \mathrm{~m}$ would introduce an underestimation. In the case of stable conditions typical for nocturnal PBL heights below $300 \mathrm{~m}$, there is almost no vertical mixing. Since the FLEXPART model uses a minimal PBL height of $100 \mathrm{~m}$, a minimum of vertical mixing within this layer is assumed. FL heights below this PBL minimum are not recommended to obtain good numerical stability (Seibert and Frank, 2004; Stohl et al., 2007b). On average over all case studies, we find a negligible increase $<1 \%$ in source contributions for FL heights between 100 and $300 \mathrm{~m}$ com- pared to the fixed $300 \mathrm{~m}$ FL height. In this range, the FL height changes are buffered, which is in agreement with the findings in Pan et al. (2014). However, the local variability allows for increases as well as decreases between 4 and $8 \%$ with peaks of more than $15 \%$. In both cases, the buffering fails due to an inhomogeneous tracer particle distribution in the $300 \mathrm{~m}$ FL height. The trajectories only represent the vertical mixing in FL heights within the PBL. FL heights should thus not exceed PBL heights for surface emissions (Stohl et al., 2007b). However, the situation is different for intensive vegetation fires. Here, the dynamics of the fire fuel convection, leading to fire plume top heights that exceed local PBL heights.

For an application example, we arrange emission data of a strong fire event in Greece in August 2007 with our case study which simulates long residence times in that fire region. In $84 \%$ of the grid cells with fires, the fire plume top height exceeds the local PBL height. For the hypothetical case study, we compare the uptake of $\mathrm{CO}$ emissions within the fire plume height, the local PBL height and the constant FL heights of 300 and $100 \mathrm{~m}$. The results show that the uptake of $\mathrm{CO}$ is the lowest for the application with fire plume heights. The total $\mathrm{CO}$ source contribution is about $77 \%$ higher for the $100 \mathrm{~m}$ FL height and $60 \%$ higher for the $300 \mathrm{~m}$ FL height assumption. This confirms that the results are not very sensitive to small changes in the FL height within $300 \mathrm{~m}$ (Pan et al., 2014; Stohl et al., 2007b). For local PBL heights, the total CO source contribution is about $32 \%$ higher than for fire plume heights. This overestimation is moderate compared to the constant FL height assumptions. The PBL height might thus be a reasonable assumption when fire plume heights are not available except for a very stable and shallow PBL heights.

From this study it can be concluded that the assumption of the FL height in LPDMs is of vital importance for the relationship between emission sources and the atmospheric composition at the receptor site. While small variations in FL height up to $300 \mathrm{~m}$ are buffered to some extent, stronger variations cause major differences in the simulation of source contributions. In particular, for fire emission with variable plume heights exceeding local PBL heights, FL height assumptions below $300 \mathrm{~m}$ significantly over or underestimate the emission impact. We find an overestimation when the receptor has a large impact from lower levels close to the surface. In cases of a larger impact from upper levels, this turns into an underestimation. This error can affect two different applications: when source contributions from upwind emission sources to an observation point are quantified, their impact is over or underestimated, and when the emission flux of sources is estimated that matches the measured concentration at the downwind observation point, the source strength is over or underestimated. This error might affect emission inventories derived from observations performed at long range. In the longer term, the option for the use of variable FL heights included in LPDMs is desirable. This is particularly 
of importance for the application on fire emissions with varying emission heights.

Data availability. All data are archived at the Max Planck Institute for Chemistry in Mainz and are available on the public ftp server in subdirectory Hueser/Flexpart4CYPHEX: server: ftp://ftp.mpic.de; protocol: ftp; port: 21; username: anonymous.

Author contributions. IH conducted the FLEXPART simulations, data analysis and wrote the manuscript. HH co-organised the CYPHEX campaign and supervised IH. AH extracted data from ECMWF and co-wrote the manuscript. JK provided CO emissions from GFASv1.2 and co-wrote the manuscript.

Competing interests. The authors declare that they have no conflict of interest.

Acknowledgements. This study was conducted for the CYPHEX campaign and was funded by the Max Planck Society (MPG). The work on fire emissions was funded by the European Union through the CAMS_44 contract with ECMWF. Furthermore, we thank ECMWF for permitting access to the operational archive.

The article processing charges for this open-access publication were covered by the Max Planck Society.

Edited by: Silvia Kloster

Reviewed by: two anonymous referees

\section{References}

Andreae, M., Rosenfeld, D., Artaxo, P., Costa, A., Frank, G., Longo, K., and Silva-Dias, M. A. F.: Smoking Rain Clouds over the Amazon, Science, 303, 1337-1342, 2004.

Dahlkötter, F., Gysel, M., Sauer, D., Minikin, A., Baumann, R., Seifert, P., Ansmann, A., Fromm, M., Voigt, C., and Weinzierl, B.: The Pagami Creek smoke plume after long-range transport to the upper troposphere over Europe - aerosol properties and black carbon mixing state, Atmos. Chem. Phys., 14, 6111-6137, https://doi.org/10.5194/acp-14-6111-2014, 2014.

Damoah, R., Spichtinger, N., Servranckx, R., Fromm, M., Eloranta, E. W., Razenkov, I. A., James, P., Shulski, M., Forster, C., and Stohl, A.: A case study of pyro-convection using transport model and remote sensing data, Atmos. Chem. Phys., 6, 173185, https://doi.org/10.5194/acp-6-173-2006, 2006.

Derstroff, B., Hüser, I., Bourtsoukidis, E., Crowley, J. N., Fischer, H., Gromov, S., Harder, H., Janssen, R. H. H., Kesselmeier, J., Lelieveld, J., Mallik, C., Martinez, M., Novelli, A., Parchatka, U., Phillips, G. J., Sander, R., Sauvage, C., Schuladen, J., Stónner, C., Tomsche, L., and Williams, J.: Volatile organic compounds (VOCs) in photochemically aged air from the eastern and western Mediterranean, Atmos. Chem. Phys., 17, 9547-9566, https://doi.org/10.5194/acp-17-9547-2017, 2017.
Duck, T. J., Firanski, B. J., Millet, D. B., Goldstein, A. H., Allan, J., Holzinger, R., Worsnop, D. R., White, A. B., Stohl, A., Dickinson, C. S., and van Donkelaar, A.: Transport of forest fire emissions from Alaska and the Yukon Territory to Nova Scotia during summer 2004, J. Geophys. Res.-Atmos., 112, d10S44, https://doi.org/10.1029/2006JD007716, 2007.

Forster, C., Wandinger, U., Wotawa, G., James, P., Mattis, I., Althausen, D., Simmonds, P., O’Doherty, S., Jennings, S. G., Kleefeld, C., Schneider, J., Trickl, T., Kreipl, S., Jäger, H., and Stohl, A.: Transport of boreal forest fire emissions from Canada to Europe, J. Geophys. Res.-Atmos., 106, 22887-22906, https://doi.org/10.1029/2001JD900115, 2001.

Kaiser, J. W., Heil, A., Andreae, M. O., Benedetti, A., Chubarova, N., Jones, L., Morcrette, J.-J., Razinger, M., Schultz, M. G., Suttie, M., and van der Werf, G. R.: Biomass burning emissions estimated with a global fire assimilation system based on observed fire radiative power, Biogeosciences, 9 , 527-554, https://doi.org/10.5194/bg-9-527-2012, 2012.

Kljun, N., Rotach, M., and Schmid, H.: A three-dimensional backward lagrangian footprint model for a wide range of boundary-layer stratifications, Bound.-Lay. Meteorol., 103, 205226, https://doi.org/10.1023/A:1014556300021, 2002.

Lal, S., Venkataramani, S., Chandra, N., Cooper, O. R., Brioude, J., and Naja, M.: Transport effects on the vertical distribution of tropospheric ozone over western India, J. Geophys. Res.-Atmos., 119, 10012-10026, https://doi.org/10.1002/2014JD021854, 2014.

Lelieveld, J., Evans, J. S., Fnais, M., Giannadaki, D., and Pozzer, A.: The contribution of outdoor air pollution sources to premature mortality on a global scale, Nature, 525, 367-371, https://doi.org/10.1038/nature15371, 2015.

Pan, X. L., Kanaya, Y., Wang, Z. F., Tang, X., Takigawa, M., Pakpong, P., Taketani, F., and Akimoto, H.: Using Bayesian optimization method and FLEXPART tracer model to evaluate CO emission in East China in springtime, Environ. Sci. Pollut. R., 21, 3873-3879, https://doi.org/10.1007/s11356-013-2317-2, the online version of this article contains supplementary material, which is available to authorized users, 2014.

Paugam, R., Wooster, M., Atherton, J., Freitas, S. R., Schultz, M. G., and Kaiser, J. W.: Development and optimization of a wildfire plume rise model based on remote sensing data inputs - Part 2, Atmos. Chem. Phys. Discuss., 15, 9815-9895, https://doi.org/10.5194/acpd-15-9815-2015, 2015.

Poupkou, A., Markakis, K., N.Liora, Giannaros, T. M., Zanis, P., Im, U., Daskalakis, N., Myriokefalitakis, S., Kaiser, J. W., Melas, D., Kanakidou, M., Karacostas, T., and Zerefos, C.: A modeling study of the impact of the 2007 Greek forest fires on the gaseous pollutant levels in the Eastern Mediterranean, Atmos. Environ., 148, 1-17, https://doi.org/10.1016/j.atmosres.2014.05.015, 2014.

Rémy, S., Veira, A., Paugam, R., Sofiev, M., Kaiser, J. W., Marenco, F., Burton, S. P., Benedetti, A., Engelen, R. J., Ferrare, R., and Hair, J. W.: Two global data sets of daily fire emission injection heights since 2003, Atmos. Chem. Phys., 17, 2921-2942, https://doi.org/10.5194/acp-17-2921-2017, 2017.

Rodean, H. C.: Stochastic Lagrangian models of turbulent diffusion, Meteor. Mon., 48, 1-84, https://doi.org/10.1175/00659401-26.48.1, 1996. 
Schmid, H. P.: Source areas for scalars and scalar fluxes, Bound.-Lay. Meteorol., 67, 293-318, https://doi.org/10.1007/BF00713146, 1994.

Seibert, P. and Frank, A.: Source-receptor matrix calculation with a Lagrangian particle dispersion model in backward mode, Atmos. Chem. Phys., 4, 51-63, https://doi.org/10.5194/acp-4-512004, 2004.

Stohl, A.: Computation, accuracy and applications of trajectories - a review and bibliography, Atmos. Environ., 32, 947-966, https://doi.org/10.1016/S1352-2310(97)00457-3, 1998.

Stohl, A. and Thomson, D. J.: A density correction for Lagrangian particle dispersion models, Bound.-Lay. Meterol., 155167, 1999.

Stohl, A., Hittenberger, M., and Wotawa, G.: Validation of the Lagrangian particle dispersion model FLEXPART against large scale tracer experiment data, Atmos. Environ., 32, 4245-4264, https://doi.org/10.1016/S1352-2310(98)00184-8, 1998.

Stohl, A., Eckhardt, S., Forster, C., James, P., Spichtinger, N., and Seibert, P.: A replacement for simple back trajectory calculations in the interpretation of atmospheric trace substance measurements, Atmos. Environ., 36, 4635-4648, https://doi.org/10.1016/S1352-2310(02)00416-8, 2002.

Stohl, A., Forster, C., Frank, A., Seibert, P., and Wotawa, G.: Technical note: The Lagrangian particle dispersion model FLEXPART version 6.2, Atmos. Chem. Phys., 5, 2461-2474, https://doi.org/10.5194/acp-5-2461-2005, 2005.

Stohl, A., Berg, T., Burkhart, J. F., Fjæraa, A. M., Forster, C., Herber, A., Hov, Ø., Lunder, C., McMillan, W. W., Oltmans, S., Shiobara, M., Simpson, D., Solberg, S., Stebel, K., Ström, J., Tørseth, K., Treffeisen, R., Virkkunen, K., and Yttri, K. E.: Arctic smoke - record high air pollution levels in the European Arctic due to agricultural fires in Eastern Europe in spring 2006, Atmos. Chem. Phys., 7, 511-534, https://doi.org/10.5194/acp-7511-2007, 2007a.
Stohl, A., J. F. Burkhart, S. E., Hirdman, D., and Sodemann, H.: An integrated internet-based system for analyzing the influence of emission sources and atmospheric transport on measured concentrations of trace gases and aerosols, Tech. rep., Norwegian Institute for Air Research, Kjeller, Norway, 2007b.

Stohl, A., Seibert, P., Arduini, J., Eckhardt, S., Fraser, P., Greally, B. R., Lunder, C., Maione, M., Mühle, J., O’Doherty, S., Prinn, R. G., Reimann, S., Saito, T., Schmidbauer, N., Simmonds, P. G., Vollmer, M. K., Weiss, R. F., and Yokouchi, Y.: An analytical inversion method for determining regional and global emissions of greenhouse gases: Sensitivity studies and application to halocarbons, Atmos. Chem. Phys., 9, 1597-1620, https://doi.org/10.5194/acp-9-1597-2009, 2009.

Stull, R.: An Introduction to Boundary Layer Meteorology, Atmospheric and Oceanographic Sciences Library, Springer Netherlands, 1988.

Stull, R.: 9 - the atmospheric boundary layer, in: Atmospheric Science, 2nd edn., edited by: Wallace, J. M. and Hobbs, P. V., Academic Press, San Diego, 375-417, https://doi.org/10.1016/B9780-12-732951-2.50014-4, 2006.

Tyrlis, E., Tymvios, F. S., Giannakopoulos, C., and Lelieveld, J.: The role of blocking in the summer 2014 collapse of Etesians over the eastern Mediterranean, J. Geophys. Res.-Atmos., 120, 6777-6792, https://doi.org/10.1002/2015JD023543, 2015.

Van Dam, B., Helmig, D., Burkhart, J. F., Obrist, D., and Oltmans, S. J.: Springtime boundary layer O3 and GEM depletion at Toolik Lake, Alaska, J. Geophys. Res.-Atmos., 118, 3382-3391, https://doi.org/10.1002/jgrd.50213, 2013.

Vardoulakis, S. and Kassomenos, P.: Sources and factors affecting $\mathrm{PM}_{10}$ levels in two European cities: implications for local air quality management, Atmos. Environ., 42, 39493963, https://doi.org/10.1016/j.atmosenv.2006.12.021, 5th International Conference on Urban Air Quality, 2008.

Vogelezang, D. and Holtslag, A.: Evaluation and model impacts of alternative boundary-layer height formulations, Bound.-Lay. Meteorol., 81, 245-269, https://doi.org/10.1007/BF02430331, 1996. 